Article

\title{
Application of Scaling-Law and CFD Modeling to Hydrodynamics of Circulating Biomass Fluidized Bed Gasifier
}

\author{
Mazda Biglari ${ }^{1}$, Hui Liu ${ }^{1}$, Ali Elkamel ${ }^{1, *}$ and Ali Lohi ${ }^{2}$ \\ 1 Department of Chemical Engineering, University of Waterloo, Waterloo, ON N2L 3G1, Canada; \\ mbiglari@uwaterloo.ca (M.B.); h34liu@engmail.uwaterloo.ca (H.L.) \\ 2 Department of Chemical Engineering, Ryerson University, Toronto, ON M5B 2K3, Canada; alohi@ryerson.ca \\ * Correspondence: aelkamel@uwaterloo.ca; Tel.: +1-519-888-4567 (ext. 37157)
}

Academic Editor: S. Kent Hoekman

Received: 26 December 2015; Accepted: 23 June 2016; Published: 30 June 2016

\begin{abstract}
Two modeling approaches, the scaling-law and CFD (Computational Fluid Dynamics) approaches, are presented in this paper. To save on experimental cost of the pilot plant, the scaling-law approach as a low-computational-cost method was adopted and a small scale column operating under ambient temperature and pressure was built. A series of laboratory tests and computer simulations were carried out to evaluate the hydrodynamic characteristics of a pilot fluidized-bed biomass gasifier. In the small scale column solids were fluidized. The pressure and other hydrodynamic properties were monitored for the validation of the scaling-law application. In addition to the scaling-law modeling method, the CFD approach was presented to simulate the gas-particle system in the small column. 2D CFD models were developed to simulate the hydrodynamic regime. The simulation results were validated with the experimental data from the small column. It was proved that the CFD model was able to accurately predict the hydrodynamics of the small column. The outcomes of this research present both the scaling law with the lower computational cost and the CFD modeling as a more robust method to suit various needs for the design of fluidized-bed gasifiers.
\end{abstract}

Keywords: fluidized bed; scaling-law; computation fluid dynamics

\section{Introduction}

Fluidized bed reactors are widely used in various industries; however, their hydrodynamic behavior, although crucial, has not been very well understood [1]. Assessment of hydrodynamic regime of a fluidized system necessitates accurate study of the individual characteristics of the fluid and solid phases (e.g., velocity and volume fraction) as well as their dual interaction (e.g., drag force exerted by fluid on particles) [2-5].

On the other hand, measurements of all necessary parameters are challenging for fluidized bed gasifiers working at high temperatures; therefore, it is useful if a model column working at ambient condition generates information required for the gasifier. Scaling laws have been used to construct a small scale model which produces identical hydrodynamic behavior as the large scale fluidized bed system [6-8]. For this purpose, scaling methods were developed based on different approaches. Good reviews on the scale up of fluidized bed combustors have been done by Leckneretal [7]. Glicksman et al. [9] made non-dimensional equations of mass and momentum conservations for solid and gas phases to develop scaling laws. Using Buckingham's Pi-theory and incorporating dominant forces in a fluidized bed system including drag, inertia, viscous and gravity forces, other scaling laws have also been developed. These scaling laws are based on the concept that generally the ratio of different forces in the two scales should be equal if hydrodynamics are going to be equivalent. The ratios yield several dimensionless groups such as Froude (Fr) $\left(u_{0}^{2} / g d_{p}\right)$, Reynolds $\left(\rho_{g} u_{0} d_{p} / \mu_{g}\right)$, and 
Archimedes $\left(g d_{p}^{3} \rho_{g}^{3}\left(\rho_{p}-\rho_{g}\right) / \mu_{g}^{2}\right)$, where $u_{0}$ is the superficial gas velocity, $g$ acceleration due to gravity, $d_{p}$ particle diameter, $\rho_{f}$ and $\rho_{p}$ densities of gas and particle respectively, and $\mu_{f}$ gas viscosity.

Other researchers recommended slightly different groups; Fitzgerald et al. [10] recommended: $g D / u_{0}^{2}, D / d_{p}, \rho_{f} / \rho_{p}, \rho_{f} u_{0} d_{p} / \mu_{f}$ where $D$ is the bed diameter, and $g D / u_{0}^{2}$ is the reciprocal of Fr defined based on bed dimension. For slugging systems, Di Felice et al. [11] added $u_{0} / u_{t}$ where $u_{t}$ is the terminal velocity of particles. Glicksman et al. [9] included $L / d_{p}$, the dimensionless particle size distribution and the sphericity, where $L$ is the bed height. For bubbling beds, Zhang and Yang [12] stated that only two groups were necessary to be equal for the two columns: $g D / u_{0}^{2}$ and $u_{0} / u_{m f}$ where $u_{m f}$ is the minimum fluidization velocity. Kehlenbeck et al. [13] used a series of numbers cited from Glicksman et al. [9] as follows:

$$
\frac{g d_{p}^{3} \rho_{f} \rho_{p}}{\mu_{f}^{2}}, \frac{\rho_{p}}{\rho_{f}}, \frac{u_{0}^{2}}{g D}, \frac{\rho_{f} u_{0} D}{\mu_{f}}, \frac{G_{p}}{\rho_{p} u_{0}} \text {, bed geometry and shape, } \varphi \text {, particles size distribution (PSD) }
$$

where $G_{p}$ is mass flux at the bottom of bed (for recycling columns), and $\varphi$ is the sphericity of particles.

Although the fluidization appears to be a random phenomenon, it constitutes periodical behavior locally and globally $[14,15]$. One way to identify flow condition in fluidization systems is to use their stochastic characteristics such as pressure and density $[1,16]$. The reason is that in a low solid content fluidized bed (nearly our case) pressure fluctuation is mainly due to the gas phase hydrodynamics [17]. It means that gas phase behavior is the indicator of system dynamics. A study by Stein et al. [18] was carried out for analysis of system hydrodynamics from solid phase point of view where the frequency of particles cycle was measured.

Pressure fluctuations are usually collected as time series. According to Di Felice et al. [11], dimensionless pressure properties (signal amplitude and frequency) can be used as a powerful means to compare behavior of different fluidized systems. That is, two systems hydrodynamics are equivalent if the statistical properties of their counterpart pressure signals are similar; such properties as mean, standard deviation, probability density function and power spectral density (PSD) function [19-21]. Although the mean and variance of pressure-time series are simpler to be evaluated and compared, additional methods are to be implemented to confirm these mean-based conclusions.

The PSD of a stochastic process, with units of power per hertz, is a positive function of that process periodicity when it is transferred from time domain to frequency domain by fast Fourier transform (FFT) $[16,22]$. In the current study, to obtain PSD of the pressure data the pressure signals of the two columns are needed to be calculated. These are then compared using the signal processing toolbox of Matlab [22].

In this study the dimensionless numbers used in Glicksman et al. [23] and Nicastro and Glicksman [24] were applied to construct a small scale fluidized bed gasifier from a large scale gasifier. The model column was tested and some hydrodynamic characteristics including pressure fluctuation and minimum fluidization velocity were measured to evaluate hydrodynamic similarity between the two columns. Based on the small scale gasifier, the hydrodynamic behavior of the large scale gasifier were determined.

Two approaches, the scaling-law and CFD modeling approaches, were generally used to facilitate the design of fluidized-bed gasifiers. Compared to the CFD modeling method, the scaling-law approach is a low-computational-cost method. The calculations can be done quickly and don't require CFD software and high-performance computation facilities. This method is proved to be useful for the scale-up of fluidized-bed gasifier and can provide valuable information for the early stage of fluidized-bed gasifiers such as the conceptual design and preliminary design. In comparison, the CFD modeling approach is an expensive computational method which requires a large amount of computer resources, especially for 3D modeling of large-scale industrial fluidized-bed gasifiers. The costs of CFD software's parallel licensing and high-performance computing hardware (computer clusters and supercomputers) can be a financial burden for small industrial users. However, for industrial users 
who can afford the cost, the CFD modeling approach as a robust method can be a better choice, because it can provide more information for the detailed design of fluidized-bed gasifiers. The flow pattern, gas species distribution, and reactor temperature predicted from CFD models can be directly used to determine the sizes, shapes, and internal structures of fluidized-bed gasifiers. The CFD modeling approach is also useful for the optimization and scale-up of fluidized-bed gasifiers. Considering the shortcomings and advantages of the two modeling methods, this paper presents both of two methods to suit various needs from the different stages of fluidized-bed gasifier design (conceptual, preliminary, and detailed designs) for different industrial (small and large) users.

\section{Experimental Methods}

The large column was a cylindrical fluidized bed gasifier with $10.2 \mathrm{~cm}$ diameter and $152.4 \mathrm{~cm}$ height, having a circulating path for solid recycling. The gasifier worked under 500 to $800{ }^{\circ} \mathrm{C}$ and 1 atm to gasify wheat straw with a nominal size of $10-15 \mathrm{~mm}$, feeding at 20 to $25 \mathrm{~g} / \mathrm{s}$ to a port $30 \mathrm{~cm}$ above the gas distributer, at the bottom of gasifier.

For the modeling purposes, accurate values of the following parameters are needed: gas velocity and solid volume fraction. Solid volume fraction is of particularly fundamental interest because it affects temperature distribution and many chemical reaction rates occurring in the bed and in the freeboard [25].

To construct a small column with similar hydrodynamic behavior as the large column and running under ambient conditions, the following dimensionless groups [9,11,13], mainly borrowed from Equation (1), were used:

$$
\frac{\rho_{p}}{\rho_{f}}, \frac{g d_{p}^{3} \rho_{f} \rho_{p}}{\mu_{f}^{2}}, \frac{u_{0}^{2}}{g d_{p}}, \frac{L}{d_{p}}, \frac{D}{d_{p}}, \varphi, \text { PSD, bed geometry }
$$

The following is an explanation of the scaling stage to construct the small scale column (See Figure 1 and follow arrows; note that the sections are divided by thick lines). The type of gas (i.e., its density and viscosity) is known to be ambient air for the cold column; therefore, the density and diameter of particles in this column can be found using the first $\left(\rho_{p} / \rho_{f}\right)$ and second $\left(g d_{p}^{3} \rho_{f} \rho_{p} / \mu_{f}^{2}\right)$ groups in Equation (1b). The third group $\left(u_{0}^{2} / d_{p}\right)$ yields superficial velocity, and the fourth $\left(L / d_{p}\right)$ and fifth $\left(D / d_{p}\right)$ groups specify $L$ and $D$, height and diameter of the column, respectively.

\begin{tabular}{|c|c|c|c|c|c|c|c|c|c|c|c|c|c|c|}
\hline & $\begin{array}{c}\mathrm{T} \\
\left({ }^{\circ} \mathrm{C}\right)\end{array}$ & $\begin{array}{c}\mathrm{P} \\
(\mathrm{atm})\end{array}$ & $\begin{array}{c}\rho_{\mathrm{f}} \\
\left(\mathrm{g} / \mathrm{m}^{3}\right)\end{array}$ & $\begin{array}{c}\rho_{\mathrm{p}} \\
\left(\mathrm{g} / \mathrm{m}^{3}\right)\end{array}$ & $\rho_{\mathrm{f}} / \rho_{\mathrm{p}}$ & $\begin{array}{c}\mathrm{d}_{\mathrm{p}} \\
(\mathrm{m})\end{array}$ & $\begin{array}{c}\mu_{\mathrm{f}} \\
(\mathrm{g} / \mathrm{m} / \mathrm{s})\end{array}$ & $d_{p}^{3} \rho_{\mathrm{f}} \rho_{\mathrm{p}} \mathrm{g} / \mu_{\mathrm{f}}^{2}$ & $\left.\begin{array}{c}\mathrm{u}_{0} \\
(\mathrm{~m} / \mathrm{s})\end{array}\right)$ & $\mathrm{u}_{0}^{2} / \mathrm{gd}_{\mathrm{p}}$ & $\begin{array}{c}\mathrm{L} \\
(\mathrm{m})\end{array}$ & $\mathrm{L} / \mathrm{d}_{\mathrm{p}}$ & $\begin{array}{c}\mathrm{D} \\
(\mathrm{m})\end{array}$ & $\mathrm{D} / \mathrm{d}_{\mathrm{p}}$ \\
\hline $\begin{array}{l}\text { Hot } \\
\text { bed }\end{array}$ & 800 & 1 & 330 & 300,000 & 0.0011 & 0.0100 & $\mid 0.0418$ & $5.6 \times 10^{5}$ & 11 & 1235 & 1.22 & $\{122$ & $|0.102|$ & $\vec{a} 0.2$ \\
\hline $\begin{array}{l}\text { Cold } \\
\text { bed }\end{array}$ & 20 & 1 & 1200 & $1,090,909$ & 0.0011 & 0.0024 & $|0.0181|$ & $5.6 \times 10^{5}$ & 5.4 & 1235 & 0.29 & 122 & 0.025 & 10.2 \\
\hline
\end{tabular}

Figure 1. Estimation of the small column (cold bed) dimensions, particle properties, and gas specifications in the small column based on the large column (hot bed).

With some minor relaxations of Geldart's particle classification [23], Figure 1 shows that the scaling rules specify that particles of group B with density $>1.1 \mathrm{~g} / \mathrm{cm}^{3}\left(>1.4 \mathrm{~g} / \mathrm{cm}^{3}\right.$ in Geldart's classification) should be used in the small column to imitate the hydrodynamic behaviour of particles of group A (density $<1.1 \mathrm{~g} / \mathrm{cm}^{3}$ ) in the large column.

The last three dimensionless groups in Equation (1) were considered as the following: the sphericity $(\phi)$ of particles in the cold bed was approximately 1 ; for the fibrous material in the hot bed, it was partially considered as follows: the feeding wheat straw was composed of the particles of 
approximately 1 to $10 \mathrm{~mm}$ length by $1 \mathrm{~mm}$ width and $0.2 \mathrm{~mm}$ thickness. Accordingly, the sphericity was varied from 0.39 to 0.83 .

For particle size scaling, a single value was used (which was scaled from the nominal particle size in the PSD of the large column) rather than having size distribution for spherical particles. Finally, the two bed geometries were identical: both cylindrical, in both columns the probes had similar shapes and installations, and both columns had a ratio of length/diameter $\approx 11.5$.

Due to the unavailability of particle size predicted in Figure 1, particles as close as possible were used (nylon). Table 1 presents the typical dimensionless numbers for particles of size $2.38 \mathrm{~mm}$ and density $1130 \mathrm{~kg} / \mathrm{m}^{3}$. The columns characteristics in Figure 1 were used for calculations.

Table 1. Actual dimensionless numbers corresponding to two columns.

\begin{tabular}{ccc}
\hline Parameter & Large Bed & Small Bed \\
\hline$T^{\circ} \mathrm{C}$ & 800 & 20 \\
$P$ atm & 1 & 1 \\
$d_{p} \mathrm{~mm}$ & 10 & 2.38 \\
$D \mathrm{~cm}$ & 10.16 & 2.5 \\
$\rho_{p} \mathrm{~kg} / \mathrm{m}^{3}$ & 300 & 1130 \\
$\rho_{f} \mathrm{~kg} / \mathrm{m}^{3}$ & 0.33 & 1.2 \\
$\mu_{f} \mathrm{~kg} / \mathrm{m} / \mathrm{s}$ & $4.18 \times 10^{-5}$ & $1.81 \times 10^{-5}$ \\
$u_{0} \mathrm{~m} / \mathrm{s}$ & 11 & 5.5 \\
$L / d_{p}$ & 122 & 122 \\
$D / d_{p}$ & 10.2 & 10.5 \\
$\rho_{p} / \rho_{f}$ & 956 & 942 \\
$\rho_{p} \rho_{f} d_{p}{ }^{3} g / \mu_{f}^{2}$ & $5.3 \times 10^{5}$ & $5.5 \times 10^{5}$ \\
$u_{0}^{2} / g d_{p}$ & 1234 & 1307 \\
$\rho_{f} u_{0} d_{p} / \mu_{f}$ & 826 & 912 \\
\hline
\end{tabular}

Table 1 indicates that the five dimensionless groups $\left(L / d_{p}, D / d_{p}, \rho_{p} / \rho_{f}, \rho_{p} \rho_{f} d_{p}{ }^{3} g / \mu_{f}^{2}, u_{0}^{2} / g d_{p}\right)$ are nearly equal for the two columns. Such closeness is considered tolerable for this analysis. The Reynolds number $\left(\rho_{f} \mathrm{u}_{0} d_{p} / \mu_{f}\right)$ was also added for an additional confirmation of proper scaling [13].

If the scaling groups calculated for an atmospheric fluidized bed operating at $800{ }^{\circ} \mathrm{C}$ and a model column at ambient condition are equal, the ratio of characteristics of the cold column to the hot column would be: linear dimensions (diameter and height) $=0.25$, particle diameters $=0.25$, particle densities $=3.5$, and superficial air velocities $=0.5[24]$.

Based on the scaling down of the large column data and the above values, a small column of polyethylene with $2.5 \mathrm{~cm}$ in diameter and $33 \mathrm{~cm}$ in height having a recycling tube was constructed, as shown in Figure 2. The ambient air was dried, metered, and purged to the bottom of column to fluidize spherical particles. The bulk density of wheat straw (large column) was measured to be very close to $300 \mathrm{~kg} / \mathrm{m}^{3}$. Scaling down criteria resulted in a particle density of $1091 \mathrm{~kg} / \mathrm{m}^{3}$ in the small column. Since particles of exact calculated density were not available, nylon particles with closest density of $1130 \mathrm{~kg} / \mathrm{m}^{3}$ were implemented for further study.

The primary parameters measured in the small column included the minimum fluidization velocity of gas and internal gas pressure. The measurement was carried out in duplicates for verification. Pressure fluctuations were selected as an indicator of fluidizing system dynamics. For the large column two pressure transducers (PX292-005DI, Omega, Stamford, CT, USA) were installed; one $10 \mathrm{~cm}$ above the straw feeding port and the other $120 \mathrm{~cm}$ above the first one, located below the column outlet. For the small column the pressure transducers (Baratron 220BH-2A1-B-10, MKS Instruments, Andover, MA, USA) were installed at $10 \mathrm{~cm}$ intervals along the column with the first one $1 \mathrm{~cm}$ above the particle holding screen. Practically, for the small column, the data collected at the top two transducers (shown in Figure 2) were not utilized because pressures at only heights of 1 and $10 \mathrm{~cm}$ were of interest (considering the measurement ports of the large column). The data were 
recorded by a data logger. Minimum fluidization velocities were estimated by plotting the superficial velocity as a function of pressure drop [26].

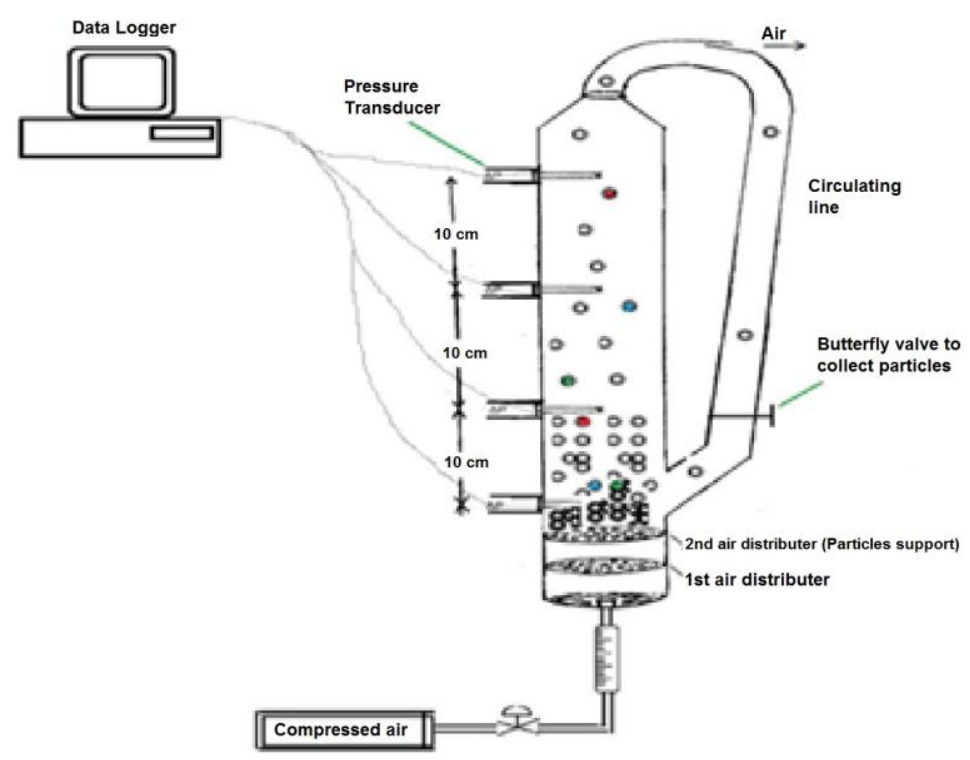

Figure 2. Small column set-up for measurement of pressure drop.

To have a broader experimental verification and insight on the effects of particle density and particle size on the hydrodynamic regime, further experiments were also conducted to include other particle densities and sizes. The densities included 950, 1130, 1350, 1800, and $2200 \mathrm{~kg} / \mathrm{m}^{3}$ and the diameters included 2.38, 3.18, 4.76, 6.35, 7.94, and $9.53 \mathrm{~mm}$.

\section{Results and Discussion}

\subsection{Pressure Profiles and Power Spectral Densities}

For both large and small columns the pressure differences were measured between the bottom and top transducers. For the hot column the distance between the two instruments was $110 \mathrm{~cm}$ and for the cold column the gap was $10 \mathrm{~cm}$. The pressure drops were measured for the entire test, but those corresponding to the fully developed fluidization of particles are shown in Figure 3. The fluctuations appear to be approximately periodical.

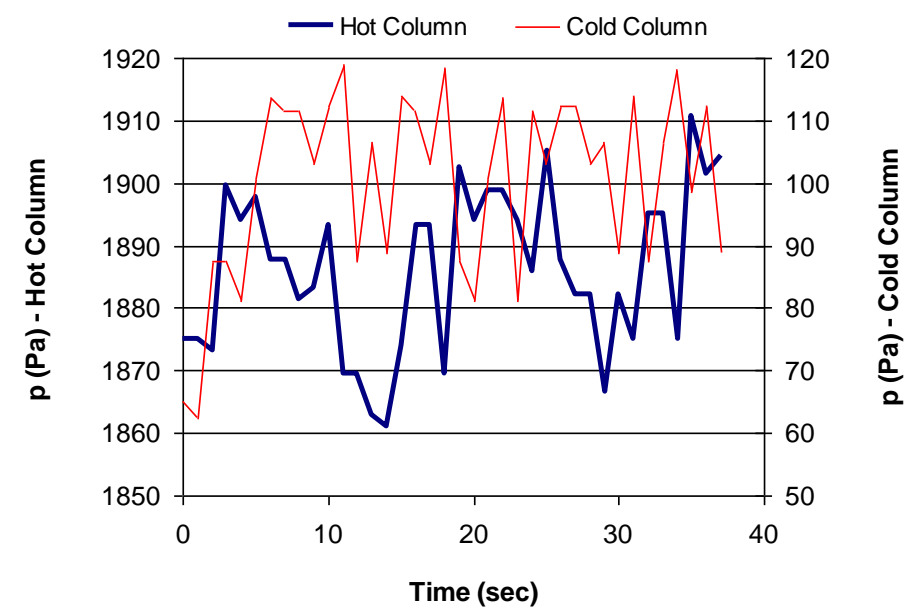

Figure 3. Comparison of pressure drops in the two columns during full fluidization. 
The primary characteristics of pressure signals (frequency and amplitude) were used to generate the power spectral density of pressure fluctuations between the two columns, using Matlab [22], shown in Figure 4.

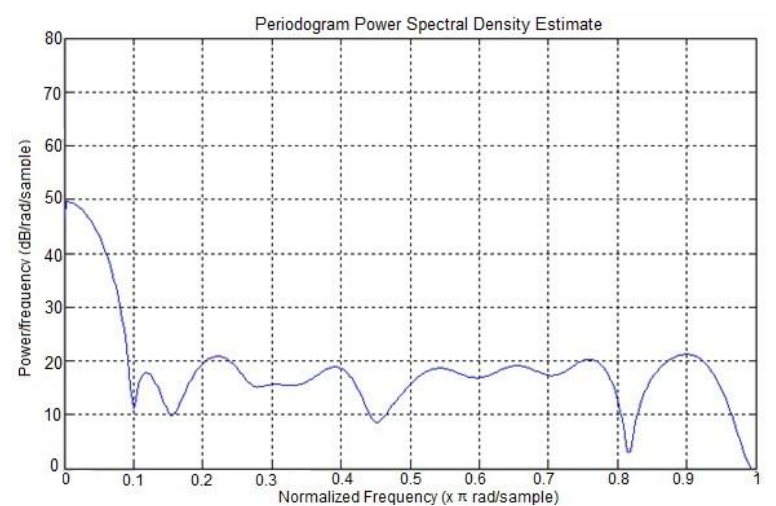

(a)

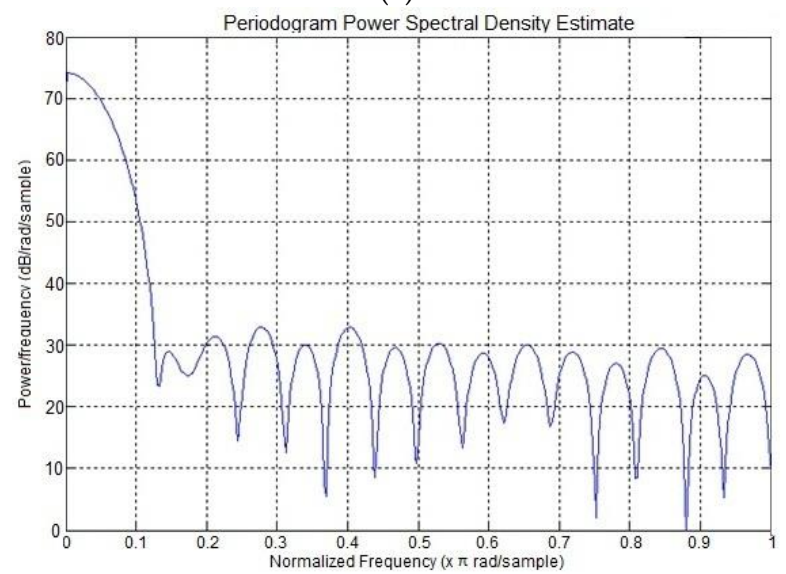

(b)

Figure 4. Power spectral density of pressure signals in (a) small column; (b) large column.

Figure 4 indicates that the frequencies in periodograms (a) and (b) are relatively similar in terms of "peaks and dips occurring at approximately the same time". As expected, the fluctuations in the hot column are more pronounced and the peaks reach higher values. Comparing the two graphs confirms that due to an approximate similarity between the two periodograms, the pressure fluctuations are similar and hence the hydrodynamic regimes in the hot and cold columns can be deemed somewhat identical.

\subsection{Application of Scaling-Law for Velocity Estimation}

Generally, two gas velocities in a fluidized bed system are important: gas superficial velocity $u_{0}$ and gas minimum fluidization velocity $u_{m f}$. The gas superficial velocity was calculated using the input gas flow rate and is important during the entire fluidization stage. In the experiment when particles of $2.38 \mathrm{~mm}$ with the density of $1130 \mathrm{~kg} / \mathrm{m}^{3}$ reached the height of $10 \mathrm{~cm}$, the air superficial velocity was measured as $5.5 \mathrm{~m} / \mathrm{s}\left(5.74 \mathrm{ft}^{3} / \mathrm{min}\right)$. The corresponding $u_{0}$ for a fully developed fluidization in the large column was $11 \mathrm{~m} / \mathrm{s}$ (cold air inflow of $17 \mathrm{ft}^{3} / \mathrm{min}$ before pre-heating).

$u_{m f}$ in the small column was estimated by plotting pressure drop across the bed versus superficial velocity. For this purpose one end of the lower transducer was left open to the atmosphere, so the transducer measured the change in the gauge pressure just above the bed when air flow rate varied. For instance, for the selected particles (nylon of size $2.38 \mathrm{~mm}$ and density $1130 \mathrm{~kg} / \mathrm{m}^{3}$ ) air flow rate and pressure were recorded. Commencing from zero and increasing air flow rate, pressure drop increases 
to a maximum which is just before bed expansion. By further increase in the air flow rate the pressure drop continues to decrease until reaching a minimum after which pressure drop increases again.

For nylon particles of $2.38 \mathrm{~mm}$ and $1130 \mathrm{~kg} / \mathrm{m}^{3}$ when volumetric flow rate increased to $1.09 \mathrm{ft}^{3} / \mathrm{min}\left(u_{0}=1.05 \mathrm{~m} / \mathrm{s}\right)$ the particles reached incipient of fluidization; hence for those particles $u_{m f}=1.05 \mathrm{~m} / \mathrm{s}$. Monitoring (at duplicates) of the pressure profiles for all particles (different sizes and densities) provided their $u_{m f}$. Figure 5 presents the results of $u_{m f}$ versus the pressure drop right at the $u_{0}=u_{m f}$.

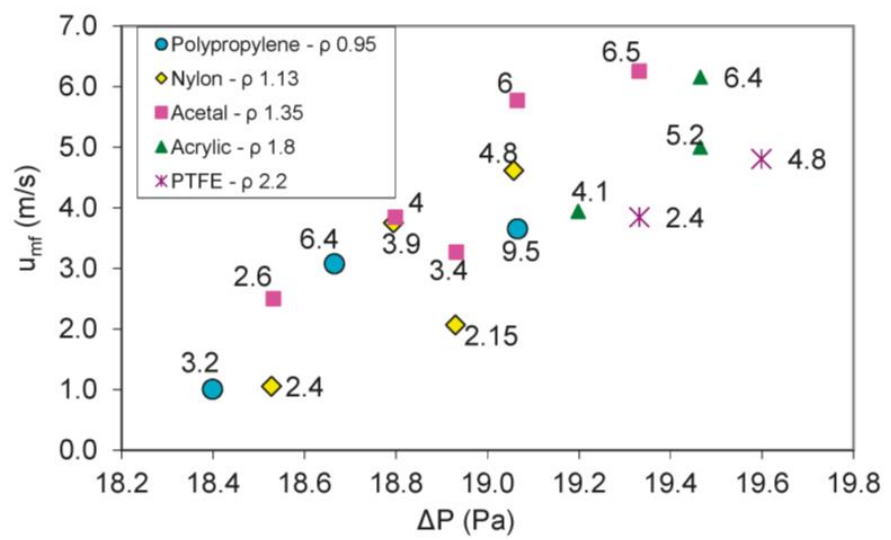

Figure 5. Minimum fluidization velocity vs. pressure drop for different particles. (Density, $\rho$, in $\mathrm{g} / \mathrm{cm}^{3}$; Numbers next to each point is the particle size in $\mathrm{mm}$ )

Figure 5 indicates that for one type of particles (density fixed) but different sizes, $u_{m f}$ has increased with increasing pressure drop. The data in Figure 5 are moderately scattered, although they show a reasonable trend. Generally, the relationship between pressure drop, minimum fluidization velocity, density, and particle size is highly non-linear. Shortly in the text, the Ergun equation [24] is used to predict $u_{m f}$ for comparison with the measurements.

As mentioned, $u_{m f}$ and $\Delta \mathrm{P}$ were measured twice at each case to evaluate reproducibility of the data collection method. Figure 5 also presents the variation in the measurement of the two variables for some selected particles. Based on Figure 5 data, using the method of graphing $u_{0}$ vs. $\Delta \mathrm{P}$ to estimate $u_{m f}$ involves $3 \%-14 \%$ variation in velocity and $1 \%-2 \%$ variation in pressure drop measurements (Figure 6 ). The negligible variability in pressure but higher variability in $u_{m f}$ were expected as the former was instrumentally measured and the latter was visually estimated.

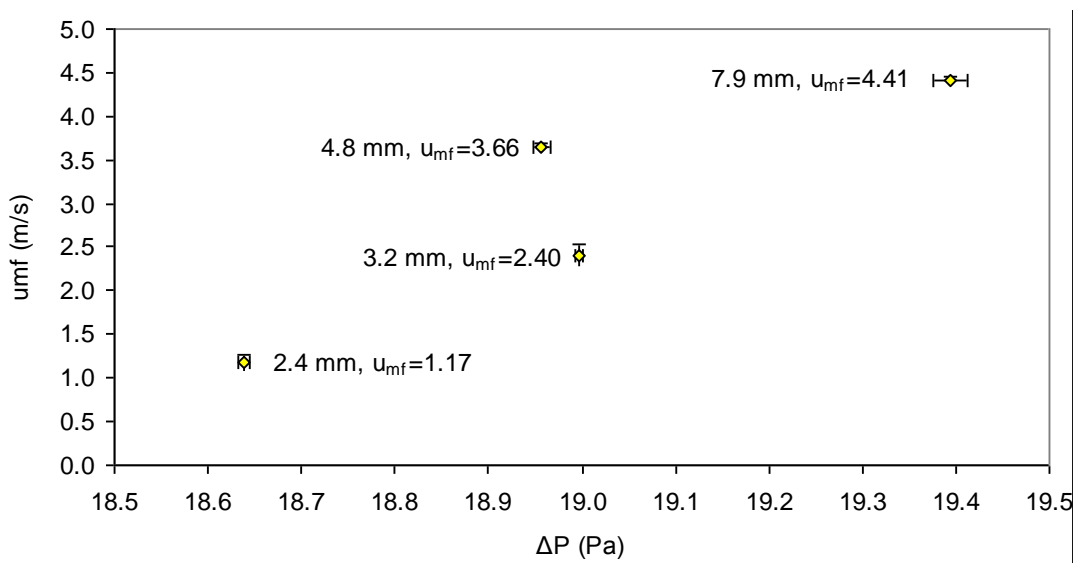

Figure 6. Reproducibility of $u_{m f}$ estimation method for different particle sizes (particles diameter are given in $\mathrm{mm})$. 
The following approach provides theoretical estimation of $u_{m f}$ using the Ergun equation [26,27]. This equation, when $u_{g a s}$ is replaced by $u_{m f}$ and $\varepsilon$ (voidage) is replaced by the voidage at fluidizing incipient $\left(\varepsilon_{m f}\right)$, yields:

$$
\left(1-\varepsilon_{m f}\right)\left(\rho_{p}-\rho_{f}\right) g=150\left(\frac{\left(1-\varepsilon_{m f}\right)^{2}}{\varepsilon_{m f}^{3}}\right)\left(\frac{\mu u_{m f}}{d_{p}^{2}}\right)+1.75\left(\frac{\left(1-\varepsilon_{m f}\right)}{\varepsilon_{m f}^{3}}\right)\left(\frac{\rho_{f} u_{m f}^{2}}{d_{p}}\right)
$$

A proper relationship between particles sphericity $(\varphi)$ and $\varepsilon_{m f}$ such as Equation (3) can be utilized:

$$
\frac{1}{\varphi^{2} \varepsilon_{m f}^{3}}=14
$$

According to CoulsonandHarker [26] and after some manipulation of Equation (18) together with Equation (19) the following equation is found for a wide range of $\varphi_{\mathrm{s}}$ and $\varepsilon_{m f}$.

$$
\operatorname{Re}_{m f}=33.65\left(\sqrt{1+6.18 \times 10^{-5} A r}-1\right)
$$

Using the definition of Reynolds number, $u_{m f}$ can then be found:

$$
u_{m f}=\left(\frac{\mu}{d_{p} \rho_{f}}\right) \operatorname{Re}_{m f}
$$

Adopting this approach, $\operatorname{Re}_{m f}$ for nylon particles $\left(\rho_{p}=1.13 \mathrm{~g} / \mathrm{cm}^{3}, d_{p}=2.38 \mathrm{~mm}\right)$ was found to be 183 , resulting in $u_{m f}$ to be $1.16 \mathrm{~m} / \mathrm{s}$, a value quite close to the measured minimum fluidizing velocity of $1.05 \mathrm{~m} / \mathrm{s}$. Note that the measured value is based on a simple visual inspection and is subject to potential errors, although velocity measurements were carried out in duplicates and the results are the average of the two measurements.

It is notable also that Ergun equation can be directly used to calculate $u_{m f}$. However, the purpose in using this indirect method is to make use of Ar and Re numbers, the non-dimensional groups used in scaling up which are hydrodynamic indicators of the system (Table 1).

The results presented above indicated that for the small column when nylon particles (as scaled particles) were utilized, the $u_{m f}$ was relatively accurately predicted by Equations (4) and (5). Therefore the approach can be used for the large column calculations as well.

\subsection{Application of Froude Numbers}

Stein et al. [16] showed that if between two columns Froude numbers $\left(\mathrm{Fr}=\left(u_{0}-u_{m f}\right) / \sqrt{g D}\right.$ or $u_{m f} / \sqrt{g D}$ or the square of them) are equal, then their particle circulation frequencies are equal too. The Fr was calculated between the two columns and was presented in Table 2.

Table 2. Comparison of $u_{0}-u_{m f} / \sqrt{g D}$ and $u_{m f} / \sqrt{g D}$ for the two columns.

\begin{tabular}{ccc}
\hline Parameter & Large Bed & Small Bed \\
\hline$d_{p}(\mathrm{~mm})$ & 10 & 2.38 \\
$\rho_{p}\left(\mathrm{~kg} / \mathrm{m}^{3}\right)$ & 300 & 1130 \\
$\rho_{f}\left(\mathrm{~kg} / \mathrm{m}^{3}\right)$ & 0.33 & 1.2 \\
$G_{p}(\mathrm{~kg} / \mathrm{m} / \mathrm{s})$ & $4.18 \times 10^{-5}$ & $1.81 \times 10^{-5}$ \\
$D(\mathrm{~cm})$ & 10.16 & 2.5 \\
$\rho_{f} u_{0} d_{p} / \mu(-)$ & 167 & 167 \\
$u_{m f}(\mathrm{~m} / \mathrm{s})$ & 2.25 & 1.05 \\
$u_{0}($ Fully Fluidized) $(\mathrm{m} / \mathrm{s})$ & 11 & 5.5 \\
$u_{m f} / \sqrt{g D}(-)$ & $\mathbf{2 . 2 6}$ & $\mathbf{2 . 1 6}$ \\
$\left(u_{0}-u_{m f}\right) / \sqrt{g D}(-)$ & $\mathbf{8 . 7 6}$ & $\mathbf{9 . 1 7}$ \\
\hline
\end{tabular}


Comparing the last two columns of Table 2 reveals that for the two fluidized systems the calculated values of Fr are approximately equal, hence roughly the similarity of particle circulation frequencies in the two columns.

Particle size distribution has been recommended as one of the scaling parameters to be matched between the two systems [13]. In this work, particle size distributions between the two models were not completely adjusted which is a source of error. Coulson and Harker [27] stated that "in the absence of channeling, it is the shape and size of the particles that determine both the maximum porosity and the pressure drop across a given height of fluidized bed of a given depth". It was implied that since there was not any channeling during the experiments we could approximately assume that pressure drop and pressure fluctuation due to particles of one size (the average size) is equal to the pressure drop/fluctuation due to the particles of varying size. Although it is a limitation in this study, the effects of this assumption will not be significant compared to the effects of other crucial parameters such as particle velocities and densities.

\subsection{CFD Simulation Results}

2D CFD models were established in ANSYS Fluent 14.0 to simulate the hydrodynamics of the "cold" column. Three cases with $d_{p}=2.38 \mathrm{~mm}, u_{0}=1.92 \mathrm{~m} / \mathrm{s}$ and $\rho_{p}=1130 \mathrm{~kg} / \mathrm{m}^{3}$ as Case 1, $d_{p}=2.38 \mathrm{~mm}, u_{0}=5.5 \mathrm{~m} / \mathrm{s}$ and $\rho_{p}=1130 \mathrm{~kg} / \mathrm{m}^{3}$ as Case 2 , and $d_{p}=3.18 \mathrm{~mm}, u_{0}=5.5 \mathrm{~m} / \mathrm{s}$, and $\rho_{p}=950 \mathrm{~kg} / \mathrm{m}^{3}$ as Case 3 were established.

The CFD models were solved by the finite volume method in ANSYS Fluent 14. A grid with 9500 cells was applied to the CFD model. The Green-Gauss cell based method was used to calculate the gradient of the variables. The scheme of phase coupled SIMPLE was applied to couple the velocity and pressure. The convergence criterion was 0.001 and the time step was set as $1.0 \times 10^{-4}$. The simulation time is set as $40 \mathrm{~s}$. The simulation results are averaged between 20 and $40 \mathrm{~s}$ to obtain stable values in the steady-state. The computation was conducted on a cluster of the High Performance Computing Virtual Laboratory (HPCVL) using 12 Intel X5670 cores at 2.9 GHz. The model settings are shown in Table 3. For the details of the governing equations in the CFD models, please refer to Appendix A.

Table 3. Model settings.

\begin{tabular}{|c|c|c|c|}
\hline \multicolumn{4}{|c|}{ Case Settings } \\
\hline Description & Case 1 & Case 2 & Case 3 \\
\hline Particle diameter $(\mathrm{mm})$ & 3.18 & 3.18 & 2.38 \\
\hline Particle density $\left(\mathrm{kg} / \mathrm{m}^{3}\right)$ & 950 & 950 & 1130 \\
\hline Superficial gas velocity $(\mathrm{m} / \mathrm{s})$ & 1.92 & 5.5 & 5.5 \\
\hline \multicolumn{4}{|c|}{ CFD Model Settings } \\
\hline Granular temperature & \multicolumn{3}{|c|}{ Algebraic } \\
\hline Granular viscosity & \multicolumn{3}{|c|}{ Gidaspow's model } \\
\hline Solid pressure & \multicolumn{3}{|c|}{ Luo's model } \\
\hline Radial distribution & \multicolumn{3}{|c|}{ Luo's model } \\
\hline Closed-packed solid volume fraction & \multicolumn{3}{|c|}{0.63} \\
\hline Restitution coefficient of particle to particle & \multicolumn{3}{|c|}{0.9} \\
\hline Inlet conditions & \multicolumn{3}{|c|}{ Velocity Inlet } \\
\hline Drag model & \multicolumn{3}{|c|}{ Gidaspow's drag model } \\
\hline Operating pressure & \multicolumn{3}{|c|}{ Atmospheric pressure } \\
\hline Wall condition for the gas phase & \multicolumn{3}{|c|}{ No Slip } \\
\hline Wall Condition for the Solid Phase & \multicolumn{3}{|c|}{ Johnson-Jackson's Method } \\
\hline Time step size & \multicolumn{3}{|c|}{$0.0001 \mathrm{~s}$} \\
\hline Maximum iterations & \multicolumn{3}{|c|}{100} \\
\hline Spatial discretization method & \multicolumn{3}{|c|}{ 1st order upwind } \\
\hline
\end{tabular}

The solids volume fraction contours of case 1 are shown in Figure 7. Since the gas velocity of $1.92 \mathrm{~m} / \mathrm{s}$ is close to the minimum fluidization velocity, only minimum fluidization was predicted in the model, which matches our observation in the experiment. Figure 8 demonstrates the solids 
distribution between 20 and $40 \mathrm{~s}$ for Case 2 . It can be seen that when the gas velocity increases to $5.5 \mathrm{~m} / \mathrm{s}$, solids are fluidized by air at the bottom of the column and the solids bed expands. Gas bubbles are formed and rise through the solids bed.

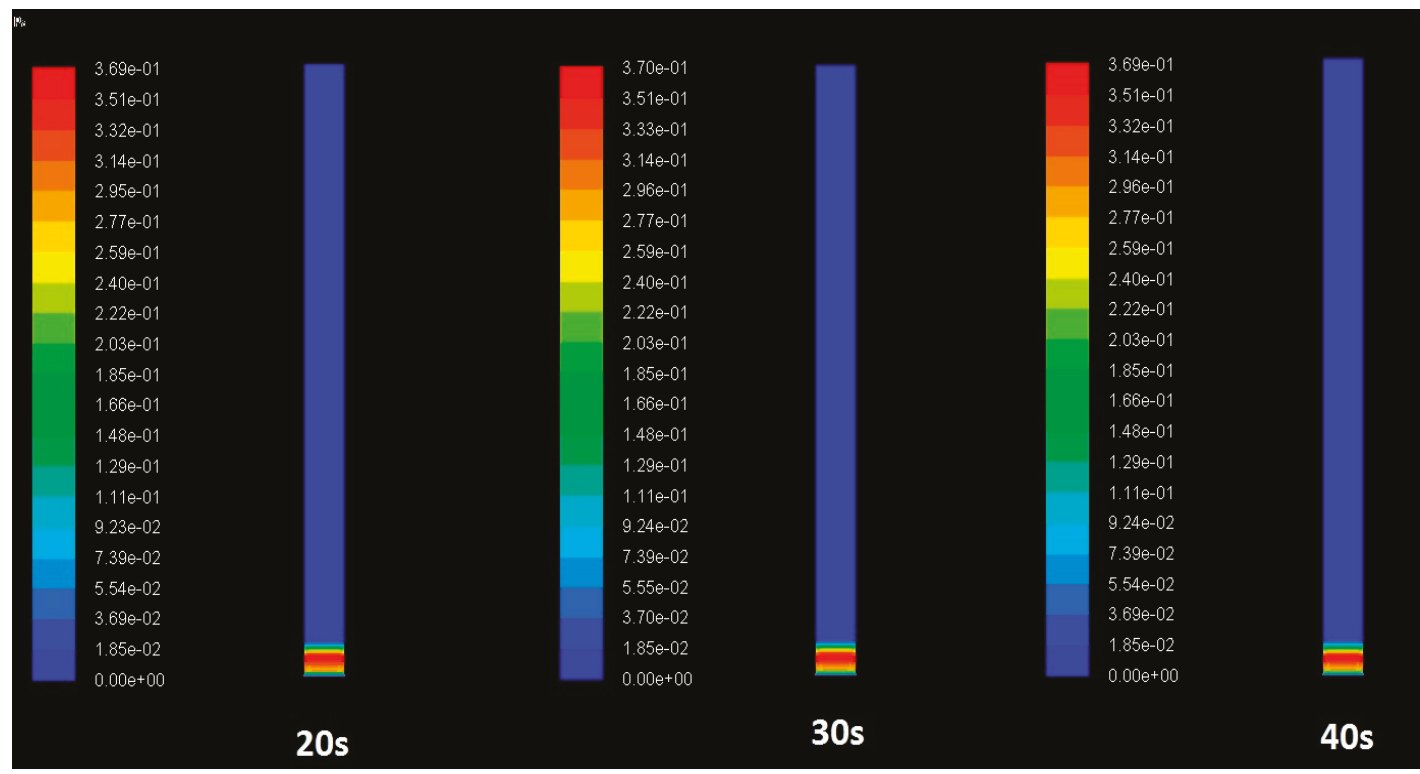

Figure 7. Solids volume fraction contour of Case 1 (20, 30, and $40 \mathrm{~s})$.

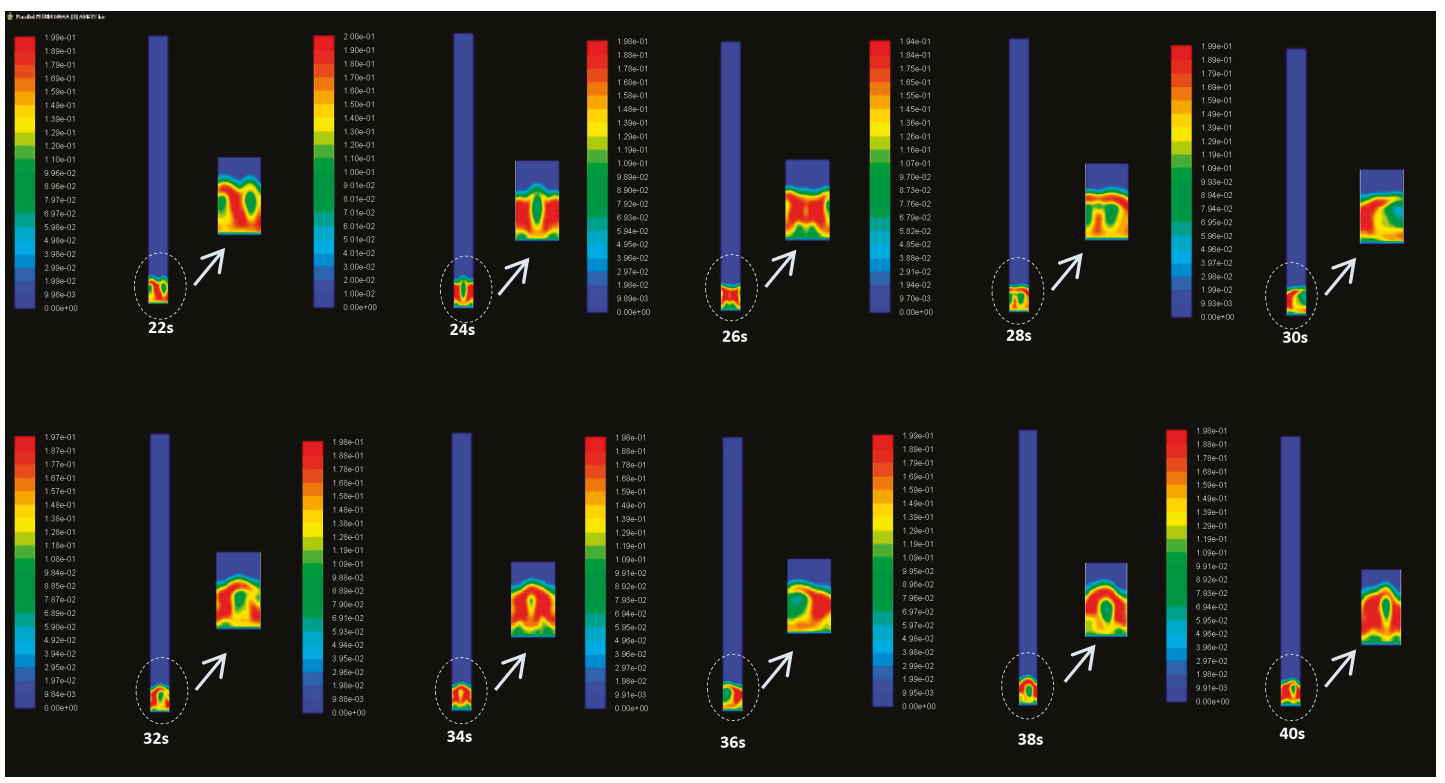

Figure 8. Solids volume fraction of Case 2 (20-40 s).

In Figure 9, the predicted pressure drops of Cases 1 and 2 are compared with the measured values in the experiment. As shown in the figure, the simulation results of Case 1 and 2 are both consistent with the experimental data. Additionally, the pressure drop from case 1 with the minimum fluidization is close to the pressure drop from case 2 with fully developed fluidization, which matches the observations by other researchers [28-30] that in fluidized-bed reactors after the minimum fluidization was reached, the bed kept expanding with the increase of gas velocity, while the pressure drop remained constant. 


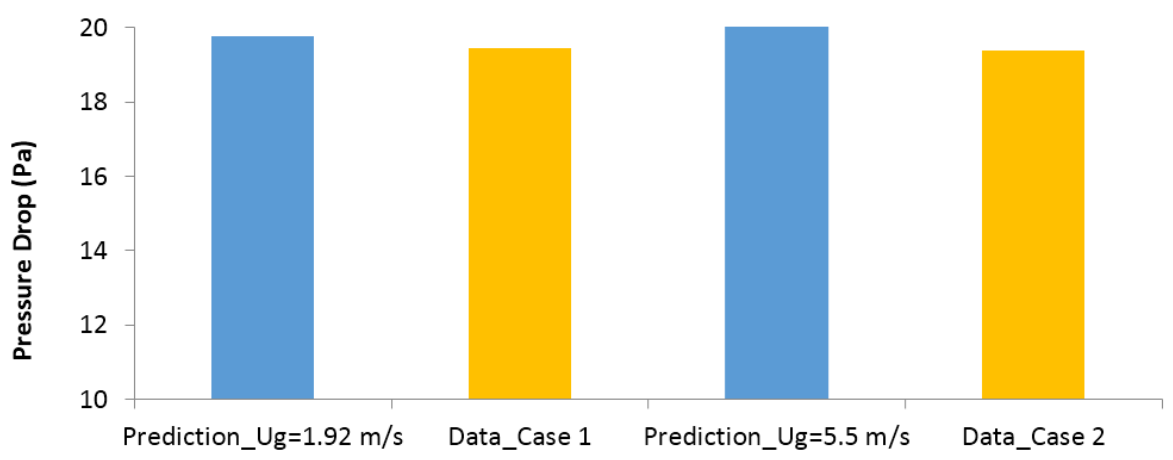

Figure 9. Predicted pressure drop vs. experimental data of Cases 1 and 2.

The solids distribution in the column for Case 3 between 20 and $40 \mathrm{~s}$ is shown in Figure 10. As seen in the figure, bubbles are generated after air is injected to the bottom of the column. The structure of solids slugging was also predicted in Case 3: the solids concentration is high in the central core region while the solids concentration becomes dilute in the near-wall region. The solids slugging may be due to bubble coalescence, high gas velocity and relatively small particles. The solids slugging can cause significant fluctuation in solid fluidization and is not recommended for normal operation of fluidized-bed reactors; however, as indicated by Kashyap et al. [30], solids slugging can provide some advantages such as avoiding solids back-mixing in the near-wall region and gas bypassing the central core region. The solids slugging structure can be measured with the technology of gamma ray densitometry $[30,31]$. Other techniques such as particle image velocimetry (PIV), laser doppler anemometry (LDA), and fiber optic probe can also be used for the measurement of solids structure in fluidized-bed reactors [31-34]. In this work the measurement of solids concentration was not done due to lack of these advanced measuring instruments; however, the measurement of solids concentration will be included in our future studies to improve the quality of our research.

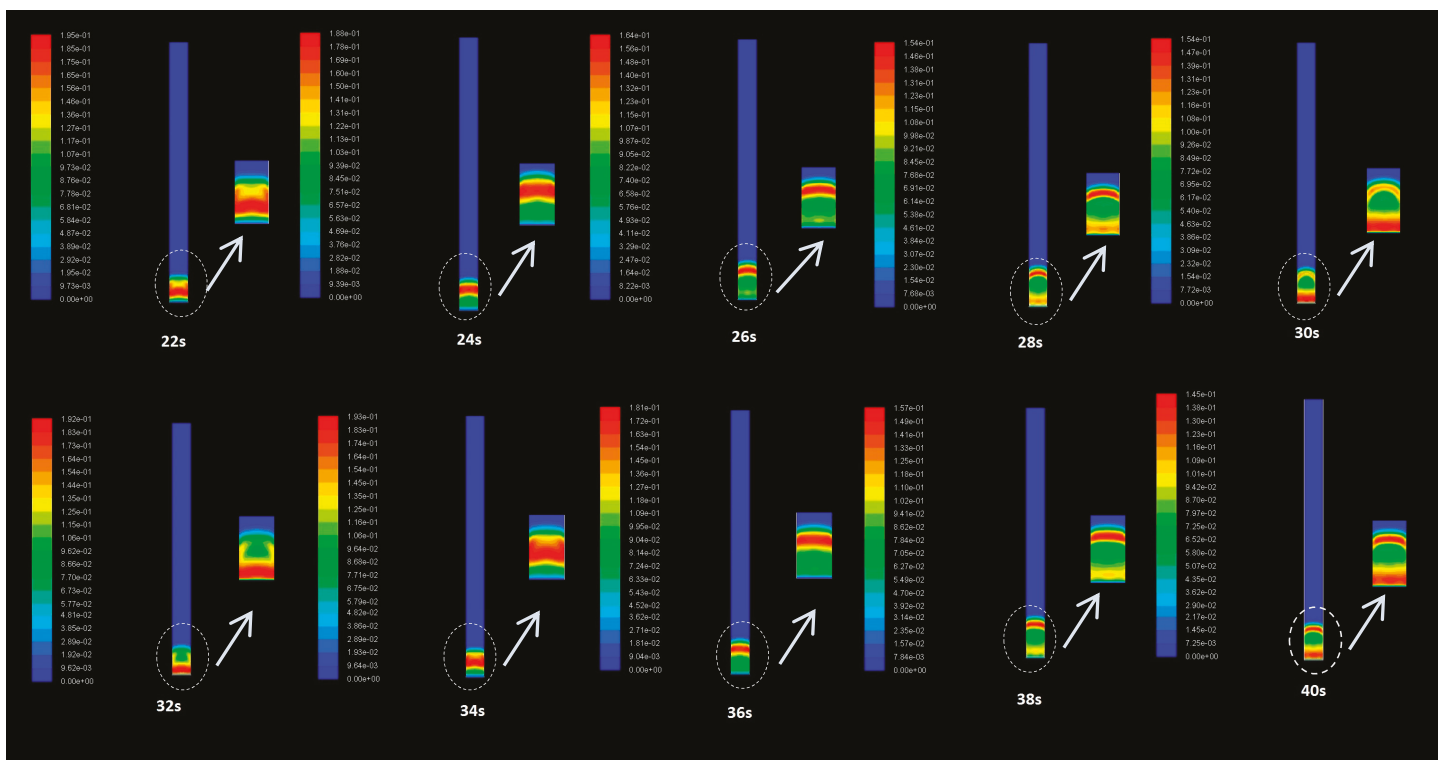

Figure 10. Solid volume fraction contour of Case 3 between 20 and $40 \mathrm{~s}$.

It is also seen that the solids bed in Case 3 expands further than that of Case 2. It is known that gas velocity, particle diameter, and solid density play important roles in solid fluidization. Given the fact that the gas velocities are the same and the solid densities are similar in Cases 2 and 3, the different fluidization patterns are mainly caused by the different diameters. Smaller particles of 2.38 
$\mathrm{mm}$ in Case 3 tend to be carried up more easily by the gas than large particles of $3.18 \mathrm{~mm}$ in Case 2 . Figure 11 shows the comparison of simulation results and experimental data and the model prediction of Case 3 demonstrates good agreement with experimental data, indicating that the current CFD model is capable of predicting the accurate flow pattern in the "cold" gasifier.

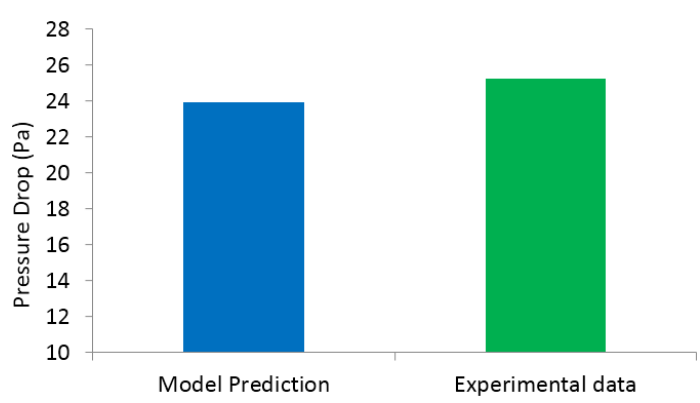

Figure 11. Predicted pressure drop vs. experimental data $\left(d_{p}=3.18 \mathrm{~mm}, \rho_{p}=950 \mathrm{~kg} / \mathrm{m}^{3}\right)$.

\section{Conclusions}

Scaling laws and dimensionless numbers were used to construct a low temperature column which models a hot fluidized bed gasifier. The model column was utilized to provide hydrodynamic characteristics of the gasifier. Power spectral densities of the two columns were compared and were shown to be approximately similar, indicating that the flow pattern and the dynamic regime of the columns are nearly identical. This similarity means that the information corresponding to the cold column can be used for the hot column. The information such as minimum fluidization velocity and solid velocity, are necessary for the design and operation of fluidized bed gasifiers. Simulation of the cold column by ANSYS Fluent indicated that the software can predict, to a good extent, the hydrodynamics of the cold column. The pressure drop in the cold column was measured and the simulation outputs were validated.

Acknowledgments: The authors would like to sincerely acknowledge ABIN, the Agricultural Biorefinery Innovation Network, and NSERC, Natural Sciences and Engineering Research Council of Canada, for providing resources and support to carry out this study. We also acknowledge the great support of the High Performance Computing Virtual Laboratory (HPCVL).

Author Contributions: Mazda Biglari designed the small scale column and helped in the design of the large column, and collected experimental results. Hui Liu performed Ansys simulation and provided the modeling aspects. Ali Elkamel and Ali Lohi co-supervised the investigation and provided feedback on the direction of research.

Conflicts of Interest: The authors declare no conflict of interest.

\section{Abbreviations}

$u_{0} \quad$ Superficial gas velocity, $\mathrm{m} / \mathrm{s}$

$g \quad$ Acceleration due to gravity, $\mathrm{m} / \mathrm{s}^{2}$

$d_{p} \quad$ Particle diameter, $\mathrm{mm}$

$\rho_{g} \quad$ Gas density, $\mathrm{kg} / \mathrm{m}^{3}$

$\rho_{p} \quad$ Particle density, $\mathrm{kgm}^{3}$

$\mu_{f} \quad$ Gas velocity, $\mathrm{kg} / \mathrm{m}, \mathrm{s}$

D Bed diameter, $\mathrm{cm}$

Fr Froude number

Re Reynolds number

Ar Archimedes number

$u_{t} \quad$ Terminal velocity, $\mathrm{m} / \mathrm{s}$

$L \quad$ Bed height, $\mathrm{m}$

$u_{m f} \quad$ Minimum fluidization velocity, $\mathrm{m} / \mathrm{s}$

$G_{p} \quad$ Mass flux, $\mathrm{kg} / \mathrm{s} / \mathrm{m}^{2}$

$\phi \quad$ Sphericity 
PSD Particle size distribution

FFT Fast Fourier transform

CFD Computational fluid dynamics

T Temperature, ${ }^{\circ} \mathrm{C}$

$P \quad$ Pressure, atm

$\triangle P \quad$ Pressure drop along column, atm

$\varepsilon_{m f} \quad$ Porosity at minimum fluidization

\section{Appendix A. Gasifier CFD Simulation}

A CFD (computational fluid dynamics) model was built to describe the hydrodynamics in the cold column. The Eulerian-Eulerian approach was applied to simulate the gas-particle system. The governing equations for the CFD model are as follows:

Continuity Equations:

$$
\begin{gathered}
\frac{\partial \alpha_{g} \rho_{g}}{\partial t}+\nabla \cdot\left(\alpha_{g} \rho_{g} v_{g}\right)=0 \\
\frac{\partial \alpha_{s} \rho_{s}}{\partial t}+\nabla \cdot\left(\alpha_{s} \rho_{s} v_{s}\right)=0
\end{gathered}
$$

where $\alpha$ is the volume fraction, $\rho$ is the density, and $v$ is the velocity; $g$ and $s$ stand for the gas and particulate phases, respectively.

Momentum Equations:

$$
\begin{gathered}
\frac{\partial\left(\alpha_{g} \rho_{g} v_{g}\right)}{\partial t}+\nabla \cdot\left(\alpha_{g} \rho_{g} v_{g} v_{g}\right)=-\alpha_{g} \nabla p+\nabla \cdot \tau_{g}+\alpha_{g} \rho_{g} g+\beta\left(v_{s}-v_{g}\right) \\
\frac{\partial\left(\alpha_{s} \rho_{s} v_{s}\right)}{\partial t}+\nabla \cdot\left(\alpha_{s} \rho_{s} v_{s} v_{s}\right)=-\alpha_{s} \nabla p-\nabla p_{s}+\nabla \cdot \tau_{s}+\alpha_{s} \rho_{s} g+\beta\left(v_{g}-v_{s}\right) \\
\tau_{g, s}=\alpha_{g, s} \mu_{g, s}\left(\nabla v_{g, s}+\nabla v_{g, s} T\right)+\alpha_{g, s}\left(\xi_{g, s}-\frac{2}{3} \mu_{g, s}\right)\left(\nabla \cdot v_{g, s}\right) \delta
\end{gathered}
$$

where $p$ is the pressure, $\mu$ is the molecular viscosity, $\xi$ is the bulk viscosity, $\beta$ is the drag coefficient, and $\delta$ is a unit tensor.

The shear viscosity and bulk viscosity of the particulate phase are estimated by the fluctuating energy equation derived from the kinetic theory of granular flow.

Fluctuating Energy Equation of Granular Flow:

$$
\begin{aligned}
& \frac{3}{2}\left[\frac{\partial \alpha_{s} \rho_{s} \Theta}{\partial t}+\nabla \cdot\left(\rho_{s} \Theta v_{s}\right)\right]=\left(p_{s} I+\tau_{s}\right): \nabla v_{s}-\nabla \cdot(\kappa \nabla \Theta)-\gamma-3 \beta \Theta \\
& p_{s}=\alpha_{s} \rho_{s} \Theta+2 \rho_{s}(1+e) \alpha_{s}^{2} g_{0} \Theta \\
& \xi_{s}=\frac{4}{3} \alpha_{s} \rho_{s} d_{s} g_{0}(1+e)\left(\frac{\Theta}{\pi}\right)^{\frac{1}{2}} \\
& g_{0}=\left[1-\left(\frac{\alpha_{s}}{\alpha_{s_{\max }}}\right)^{\frac{1}{3}}\right]^{-1} \\
& \mu_{s}=\mu_{s, c o l}+\mu_{s, k i n}+\mu_{s, f r} \\
& \mu_{s, c o l}=\frac{4}{5} \alpha_{s} \rho_{s} d_{s} g_{0}(1+e)\left(\frac{\Theta}{\pi}\right) \\
& \mu_{s, k i n}=\frac{\alpha_{s} \rho_{s} d_{s} \sqrt{\Theta \pi}}{6(3-e)}\left[1+\frac{2}{5}(1+e)(3 e-1) \alpha_{s} g_{0}\right] \\
& \mu_{s, f r}=\frac{p_{s} \sin \phi}{2 \sqrt{I_{2} D}}
\end{aligned}
$$




$$
\begin{gathered}
\kappa=\frac{150 \sqrt{\pi} \rho_{s} d_{p} \Theta^{\frac{1}{2}}}{384(1+e) g_{0}}\left[1+\frac{6}{5}(1+e) g_{0} \alpha_{s}\right]^{2}+2 \alpha_{s}{ }^{2} \rho_{s} d_{p}(1+e)\left(\frac{\Theta}{\pi}\right)^{\frac{1}{2}} \\
\gamma=\frac{12\left(1-e^{2}\right) g_{0}}{d_{s} \sqrt{\pi}} \rho_{s} \alpha_{s}{ }^{2} \Theta^{\frac{3}{2}}
\end{gathered}
$$

where $\Theta$ is the granular temperature, $\gamma$ is the collisional dissipation energy, and $g_{0}$ is the radial distribution function. $\mu_{s, c o l}, \mu_{s, k i n}$, and $\mu_{s, f r}$ are the collisional, kinetic, and frictional viscosities, respectively.

The drag coefficient is calculated by Gidaspow's model:

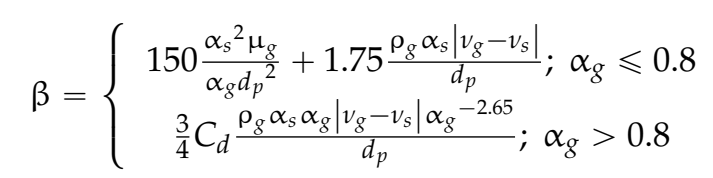

\section{References}

1. Ghasemi, F.J.; van Ommen, R.; Sahimi, M. Analysis of pressure fluctuations in fluidized beds. I. Similarities with turbulent flow. Chem. Eng. Sci. 2011, 66, 2627-2636.

2. Chalermsinsuwan, B.; Chanchuey, T.; Buakhao, W.; Gidaspow, D.; Piumsomboon, P. Computational fluid dynamics of circulating fluidized bed downer: Study of modeling parameters and system hydrodynamic characteristics. Chem. Eng. J. 2012, 189-190, 314-335. [CrossRef]

3. Di Maio, F.P.; Di Renzo, A.; Vivacqua, V. Extension and validation of the particle segregation model for bubbling gas-fluidized beds of binary mixtures. Chem. Eng. Sci. 2013, 97, 139-151. [CrossRef]

4. Dieter, H.; Bidwe, A.R.; Varela-Duelli, G.; Charitos, A.; Hawthorne, C.; Scheffknecht, G. Development of the calcium looping $\mathrm{CO}_{2}$ capture technology from lab to pilot scale at IFK, University of Stuttgart. Fuel 2014, 127, 23-37. [CrossRef]

5. Kalita, P.; Saha, U.K.; Mahanta, P. Effect of biomass blending on hydrodynamics and heat transfer behavior in a pressurized circulating fluidized bed unit. Int. J. Heat Mass Transf. 2013, 60, 531-541. [CrossRef]

6. Knowlton, T.M.; Karri, S.B.R.; Issangya, A. Scale-up of fluidized-bed hydrodynamics. Powder Technol. 2005, 150, 72-77. [CrossRef]

7. Leckner, B.; Szentannai, P.; Winter, F. Scale-up of fluidized-bed combustion-A review. Fuel 2011, 90, 2951-2964. [CrossRef]

8. Rüdisüli, M.; Schildhauer, T.J.; Biollaz, S.M.A.; van Ommen, J.R. Scale-up of bubbling fluidized bed reactors-A review. Powder Technol. 2012, 217, 21-38. [CrossRef]

9. Glicksman, L.R.; Hyre, M.R.; Farrell, P.A. Dynamic similarity in fluidization. Int. J. Multiph. Flow 1994, 20, 331-386. [CrossRef]

10. Fitzgerald, T.; Bushnell, D.; Crane, S.; Shieh, Y.-C. Testing of cold scaled bed modeling for fluidized-bed combustors. Powder Technol. 1984, 38, 107-120. [CrossRef]

11. Di Felice, R.; Rapagnà, S.; Foscolo, P.U. Dynamic similarity rules: Validity check for bubbling and slugging fluidized beds. Powder Technol. 1992, 71, 281-287. [CrossRef]

12. Zhang, M.C.; Yang, R.Y.K. On the scaling laws for bubbling gas-fluidized bed dynamics. Powder Technol. 1987, 51, 159-165. [CrossRef]

13. Kehlenbeck, R.; Yates, J.; di Felice, R.; Hofbauer, H.; Rauch, R. Novel scaling parameter for circulating fluidized beds. AIChE J. 2001, 47, 582-589. [CrossRef]

14. Van der Schaaf, J.; Schouten, J.C.; Johnsson, F.; van den Bleek, C.M. Non-intrusive determination of bubble and slug length scales in fluidized beds by decomposition of the power spectral density of pressure time series. Int. J. Multiph. Flow 2002, 28, 865-880. [CrossRef]

15. Shou, M.C.; Leu, L.P. Energy of Power Spectral Density Function and Wavelet Analysis of Absolute Pressure Fluctuation Measurements in Fluidized Beds. Chem. Eng. Res. Des. 2005, 83, 478-491. [CrossRef]

16. Pahk, J.B. Experimental Study of Pressure Fluctuation in Pneumatic Conveying by Various Methods of Analysis. Ph.D. Thesis, University of Pittsburg, Pittsburgh, PA, USA, 2006. 
17. Schouten, J.C.; van den Bleek, C.M. Monitoring the quality of fluidization using the short-term predictability of pressure fluctuations. AIChE J. 1998, 44, 48-60. [CrossRef]

18. Stein, M.; Ding, Y.L.; Seville, J.P.K. Experimental verification of the scaling relationships for bubbling gas-fluidised beds using the PEPT technique. Chem. Eng. Sci. 2002, 57, 3649-3658. [CrossRef]

19. Gómez-Hernández, J.; Sánchez-Prieto, J.; Briongos, J.V.; Santana, D. Wide band energy analysis of fluidized bed pressure fluctuation signals using a frequency division method. Chem. Eng. Sci. 2014, 105, 92-103. [CrossRef]

20. Brown, R.C.; Brue, E. Resolving dynamical features of fluidized beds from pressure fluctuations. Powder Technol. 2001, 119, 68-80. [CrossRef]

21. Sheikhi, A.; Sotudeh-Gharebagh, R.; Mostoufi, N.; Zarghami, R. Experimental investigation on the hydrodynamics of a gas-liquid-solid fluidized bed using vibration signature and pressure fluctuation analyses. Int. J. Heat Fluid Flow 2013, 42, 190-199. [CrossRef]

22. Matlab Signal Processing Toolbox, User's Guide; Mathwork Inc.: Natick, MA, USA, 2010.

23. Glicksman, L.R.; Hyre, M.; Woloshun, K. Simplified scaling relationships for fluidized beds. Powder Technol. 1993, 77, 177-199. [CrossRef]

24. Nicastro, M.T.; Glicksman, L.R. Experimental verification of scaling relationships for fluidized bed. Chem. Eng. Sci. 1984, 39, 1381-1391. [CrossRef]

25. Geldart, D. Types of gas fluidization. Powder Technol. 1973, 7, 285-292. [CrossRef]

26. Coulson, J.F.; Harker, J.H. Coulson and Richardson's Chemical Engineering. Volume 2-Particle Technology and Separation Processes, 5th ed.; Chapter 6; Butterworth-Heinemann: Oxford, UK, 2002.

27. Nemtsov, D.A.; Zabaniotou, A. Mathematical modelling and simulation approaches of agricultural residues air gasification in a bubbling fluidized bed reactor. Chem. Eng. J. 2008, 143, 10-31. [CrossRef]

28. Vollmari, K.; Jasevičius, R.; Kruggel-Emden, H. Experimental and numerical study of fluidization and pressure drop of spherical and non-spherical particles in a model scale fluidized bed. Powder Technol. 2016, 291, 506-521. [CrossRef]

29. Jena, H.M.; Roy, G.K.; Biswal, K.C. Studies on pressure drop and minimum fluidization velocity of gas-solid fluidization of homogeneous well-mixed ternary mixtures in un-promoted and promoted square bed. Chem. Eng. J. 2008, 145, 16-24. [CrossRef]

30. Vanni, F.; Caussat, B.; Ablitzer, C.; Brothier, M. Effects of reducing the reactor diameter on the fluidization of a very dense powder. Powder Technol. 2015, 277, 268-274. [CrossRef]

31. Kashyap, M.; Gidaspow, D.; Koves, W.J. Circulation of geldart D type particles: Part I-High solids fluxes. Measurements and computation under solids slugging conditions. Chem. Eng. Sci. 2011, 66, 183-206. [CrossRef]

32. Kashyap, M.; Gidaspow, D.; Koves, W.J. Circulation of geldart D type particles: Part II—Low solids fluxes: Measurements and computation under dilute conditions. Chem. Eng. Sci. 2011, 66, 1649-1670. [CrossRef]

33. Kashyap, M.; Chalermsinsuwan, B.; Gidaspow, D. Measuring turbulence in a circulating fluidized bed using PIV techniques. Particuology 2011, 9, 572-588. [CrossRef]

34. Kashyap, M.; Gidaspow, D. Measurements of Dispersion Coefficients for FCC particles in a free board. Ind. Eng. Chem. Res. 2011, 50, 7549-7565. [CrossRef]

(C) 2016 by the authors; licensee MDPI, Basel, Switzerland. This article is an open access article distributed under the terms and conditions of the Creative Commons Attribution (CC-BY) license (http://creativecommons.org/licenses/by/4.0/). 